\title{
Glucose concentrations in blood and tissue - a pilot study on variable time lag
}

\author{
Rudolf Chlup a,b,c, Jan Krejcid, Mark O'Connelle, Blanka Sebestovad ${ }^{d}$, Robert Plickad , Lucie Jezovad, Tereza Brozovad, \\ Blanka Doubravova ${ }^{c, d}$, Hana Zalesakova ${ }^{c, d}$, Emilia Durajkovad ${ }^{c, d}$, Jiri Vojtek ${ }^{d}$, Josef Bartek ${ }^{g}$
}

\begin{abstract}
Aim. The aim of this pilot study was to acquire insight into the parameters of glycaemic control, especially, (1) the time delay (lag phase) between plasma and tissue glucose concentrations in relation to rise and fall in glucose levels and (2) the rate of glucose increase and decrease.

Methods. Four healthy people (HP), 4 people with type 1 diabetes (DM1) and 4 with type 2 diabetes (DM2) underwent concurrent glucose measurements by means of (1) the continuous glucose monitoring system (CGMS-Medtronic), Medtronic-Minimed, CA, USA, calibrated by the glucometer Calla, Wellion, Austria, and, (2) the Beckman II analyser to measure glucose concentrations in venous plasma. Samples were taken on 4 consecutive days in the fasting state and 4 times after consumption of $50 \mathrm{~g}$ glucose. Carelink Personal, MS Excel, Maple and Mat lab were applied to plot the evolution of glucose concentration and analyse the results. The time difference between increase and decrease was calculated for HP, DM 1 and DM 2.

Results. In DM1 and DM2, glucose tolerance testing (GTT) resulted in slower transport of glucose into subcutaneous tissue than in HP where the lag phase lasted up to $12 \mathrm{~min}$. The maximum increase/decrease rates in DM1 and DM2 vs HP were 0.25 vs $<0.1 \mathrm{mmol} / \mathrm{L} / \mathrm{min}$.

Conclusion. CGMS is shown to provide reliable plasma glucose concentrations provided the system is calibrated during a steady state. The analysis of glucose change rates improves understanding of metabolic processes better than standard GTT.
\end{abstract}

Key words: diabetes mellitus, continuous glucose monitoring, lag phase, glucose transport, calibration

Received: October 1, 2014; Accepted with revision: January 28, 2015; Available online: March 1, 2015 http://dx.doi.org/10.5507/bp.2015.007

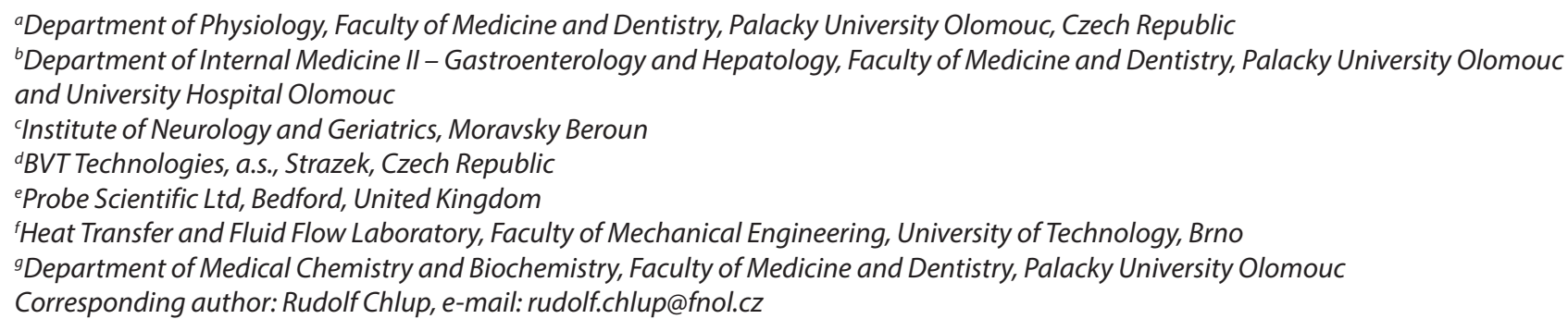

\section{INTRODUCTION}

Euglycaemic control is of paramount importance in diabetes especially in relation to preventing late diabetes complications. Several markers of glycaemic control have been used in routine practice as well as in clinical trials. Apart from clinical investigation, laboratory parameters such as quantitative glycosuria, ketonuria, fasting glycaemia, glycated serum proteins ${ }^{1}, 1.5$ - anhydroglucitol ${ }^{2}$, and concentration of haemoglobin A1c in blood are used to assess carbohydrate metabolism.

Above all plasma glucose concentrations over $24 \mathrm{~h}$ recorded as mean plasma glucose and glycaemic variability over 24 - 72 h $\left(\right.$ ref. $^{3}$ ) have become the principle parameters for guiding treatment and assess the efficacy of drugs on patient glycaemic control ${ }^{4,5}$.

From 1974, following the introduction of glucometers into daily routine, self-monitoring of plasma/ blood glucose (SMPG/SMBG) became the predominant mode of glucose monitoring ${ }^{6}$. From the year 2000 , the use of continuous glucose monitoring systems (CGMS) has shown remarkable benefits for both people with type 1 and type 2 diabetes $^{7-12}$. The development of CGMS technology is a great step toward modern diabetes management ${ }^{13}$. CGMS has also been used to investigate the glycaemic indexes of food at different times of the day ${ }^{14,15}$. This overcomes the limitations of traditional monitoring by producing glucose profiles instead of distinct measurements, real-time glucose values, glucose trends and warnings when glucose values approach dangerously low or high concentrations. In this way, frequent use of CGM systems and careful pattern analysis can improve glycaemic control ${ }^{7-10}$.

On the other hand, evaluation of the prolific data provided by CGMS often makes the implementation of CGMS in practice, difficult. The relationship between plasma glucose concentration and interstitial glucose dynamics had to be established. Rebrin concluded that differences between plasma and interstitial glucose will not be a significant obstacle in advancing the use of interstitial fluid as an alternative to plasma glucose measurements ${ }^{16}$. Thennadil compared glucose concentration in interstitial fluid and capillary and venous blood during rapid changes 
in blood glucose concentrations ${ }^{17}$. Boyne found the time lag of interstitial glucose behind plasma glucose, regardless whether glycaemia was rising or falling ${ }^{18}$.

CGMS calibration is influenced by the speed (time rate $[\mathrm{mmol} / \mathrm{L} / \mathrm{min}])$ of glucose transport between plasma, interstitium and intracellular space. Current CGMS methods derive glucose concentrations from different tissues using subcutaneous/"interstitial" values of electrical current (ISIG - Input Signal for Glucose) for measurement and whole blood/plasma for calibration. Correct calibration of subcutaneous sensors is mandatory for reliable CGMS results. However, correct calibration can be obtained only if the concentrations in plasma and tissue are the same. The measured values can be affected by several factors such as accuracy and precision of the calibrating system, variability of plasma glucose concentration resulting from food consumption or stress and muscular exercise.

The aim of this pilot study was to gain insight into the parameters of glycaemic control, especially, (1) the time delay (lag phase) between postprandial glucose concentrations in venous plasma (measured by the analyser Beckman II) and subcutaneous tissue (measured by CGMS - Medtronic calibrated by the Calla glucometerstrip system) as they increase and decrease in healthy people (HP), in persons with diabetes type 1 (DM1) and in people with diabetes type 2 (DM2), and, (2) the rates of glucose concentration increase and decrease.

\section{MATERIALS AND METHODS}

\section{Tested volunteers}

Twenty five volunteers for this pilot study (HP, DM1 and DM2) were recruited from students, hospital staff and patients at diabetes centres. Informed consent according to the most recent Helsinki Declaration was signed by all participants. The purpose and procedures of the research protocol were explained. Their rights to refrain from the trial under any circumstances and for any reason were emphasized. Clinical and laboratory investigations of all volunteers were performed on admission to day-4 of the stay in the diabetes department to confirm that they all met the criterias required for the trial (age above 18 years old, no active infection no acute disorder within 3 weeks before the trial, no haemorrhagic disorder, no malignancy, no pregnancy, no oral or injectable steroids).

All the participants agreed to the following prerequisites:

No smoking or alcohol over a period of one day before and during the 4 days of study.

Willing to keep to the defined protocol over the whole study period.

Carrying on with usual medication and insulin administration (if necessary).

People with frequent disturbances of function of venous catheter and serious deviations from the study protocol were excluded such that only twelve volunteers with complete data sets were considered for final evaluation:
HP ( $\mathrm{n}=4$, age $21-46$ y, BMI $22.0-34.7 \mathrm{~kg} / \mathrm{m}^{2}$, HbA1c 34 - $35 \mathrm{mmol} / \mathrm{mol})$; DM1 $(\mathrm{n}=4$, age $37-66 \mathrm{y}$, duration of DM1 0.- 42 y, insulin 23 - 42 IU/d, BMI 21.1 - $26.0 \mathrm{~kg} / \mathrm{m}^{2}$, HbAlc 60 - 81mmol/mol); DM2 ( $\mathrm{m}=4$, age $57-68 \mathrm{y}$, duration of DM2 up to $23 \mathrm{y}$, insulin up to $60 \mathrm{IU} / \mathrm{d}$, BMI 21.7 - $38.0 \mathrm{~kg} / \mathrm{m}^{2}$, HbA1c 50 - $\left.88 \mathrm{mmol} / \mathrm{mol}\right)$.

\section{Equipment and software}

Standard devices and programmes were:

(1)Continuous glucose monitoring system (CGMS), namely, subcutaneous sensor Enlite, for measuring the ISIG transferred by means of an external transmitter Minilink from interstitium to the monitor Guardian where it was automatically converted (using calibrating algorithm) to the values of plasma glucose concentrations, Medtronic Minimed, Northridge, CA, USA.

(2) Glucometer system Calla Premium and glucoseoxidase strips (Wellion, Austria) for measuring values of glucose concentrations in capillary plasma to calibrate the CGMS.

(3) Beckman analyser typ II to estimate glucose concentrations in venous plasma.

Software programs Carelink Personal v. 3.0 (Medtronic Minimed, Northridge, CA, USA), MS Excel, Maple and Mat lab were applied to plot the evolution of glucose concentration obtained by CGMS and by Beckman analyzer during the whole study, respectively.

\section{Study design}

This was a cross-sectional trial performed in the Diabetes Department of the Institute of Neurology and Geriatrics, Moravský Beroun, Czech Republic from October 2013 to April 2014. Approval of the Ethics Committee of the University Hospital Olomouc and Faculty of Medicine and Dentistry, Palacky University Olomouc was obtained.

Investigation of each volunteer lasted 4 days (from Friday to Monday). On the first day, one or two volunteers were admitted to one ward and remained there under the scheduled check-ups of investigators and continuous supervision of one specialized nurse until the fourth day.

On admission (Day 1), a thorough clinical investigation was performed.

Sensor Enlite was inserted by a specialized nurse into the subcutaneous tissue of the abdomen or arm and within 15 min was connected to a transmitter Minilink. The first CGMS calibration was performed two hours later (at about 10:00 h, still in the fasting state) using the value of capillary plasma glucose concentration from glucometer Calla which was manually put into the monitor Guardian. Next, the CGMS was operated according to the instructions in the Medtronic Manual. All values of glucose concentration from Calla (usually 18 per day) were put into Guardian.

On Day 1, 2, 3 and 4 in addition to the CGMS, blood samples from cubital vein were obtained using an indwelling catheter which was inserted on the first day 
and remained functioning over the whole study period or changed only if any malfunction or discomfort occurred. Venous blood was taken in the fasting state at 6:00 $\mathrm{h}$ and then each hour till 24:00, and on day 4 from 6:00 till 11:00. This venous blood was centrifuged within $5 \mathrm{~min}$ after the drawing at $2000 \mathrm{rev} / \mathrm{min}$, for $5 \mathrm{~min}$. Plasma was immediately analysed or (if taken between 14:00 and 24:00 h) stored at $-18^{\circ} \mathrm{C}$ for analysis the next day. Glucose concentrations in venous plasma were measured in all sample tubes using the Beckman analyser. Fifty grams of glucose dissolved in $300 \mathrm{~mL}$ tea or water was administered in the fasting state as a breakfast usually at 7:00 h. Following this 2-h oral glucose tolerance test (OGTT), all volunteers received standard portions of 4 different meals served at 4-hourly intervals (i.e. at 11:00 h, 15:00 h, 19:00 $\mathrm{h}$ and 23:00 h). Each portion contained $50 \mathrm{~g}$ of absorbable carbohydrates and adequate amount of proteins: 260 $\mathrm{g}$ carbohydrates, $70 \mathrm{~g}$ proteins and $88 \mathrm{~g}$ fat (i.e. a total of $8930 \mathrm{~kJ}$ ) were consumed daily on day 1,2 and 3 .

On day 4 the study ended after the OGTT at 11:00 h.

The meal plan is defined in Table 1. No additional meals or drinks were allowed.

\section{Data processing and statistic analysis}

The data from the monitor Guardian were downloaded to the therapy management software for diabetes Carelink Personal (www.carelink.minimed.com) and then exported to MS Excel to plot the daily evolution of glucose concentration obtained by CGMS and by Beckman analyser, respectively. Data from the Beckmann analyser were included manually.

For each volunteer, the time difference between increase and decrease was estimated and averaged for each HP, for DM1 and for DM2, respectively.

The data analysis was performed by our own programs created in Maple, Matlab and MS Excel. The programs were created using standard Maple and Matlab libraries and linked to Excel (graphical output). Data were processed using splines of the $3^{\text {rd }}$ order.
The results were presented using analysis of first derivative of glucose profile as the first approximation step of process description.

\section{Estimation of time delay between plasma and tissue and glucose increase/decrease rates}

The time delay between plasma and tissue during plasma glucose concentration increase (BT $\uparrow$ ) was measured as time between maximum glucose concentration increase rates in plasma and tissue. Maximum glucose concentration increase in tissue was measured by CGMS. Similarly, the time delay at glucose concentration decrease (TB $\downarrow$ ) was measured as the difference in CGMS and Beckman values at maximum decrease rates in tissue (measured by CGMS) and plasma glucose decrease rate. Both quantities are well defined from the mathematical point of view. BT $\uparrow$ is defined as the time difference between inflex points of plasma and tissue glucose concentration when the glucose concentration increases. TB $\downarrow$ is defined in the same manner when the glucose concentration in venous plasma decreases.

Capillary plasma glucose concentration was measured by the glucometer-strip (glucoseoxidase) system Calla and on the analyser Beckman II using glucoseoxidase enzyme. The best correlation between Beckman analyser and system Calla proved the accuracy of plasma glucose measurement and correct CGMS calibration using glucometer Calla.

\section{RESULTS}

Time delays between tissue and plasma are displayed in Table 2.

The result for the reliable function of CGMS is shown in Fig. 1 as an analysis of glucose increase/decrease trends. An excellent agreement in the trends of CGMS and blood/plasma is seen. The relation between trend in tissue and blood/plasma is approximately same and the same as responses to glucose load.

Table 1. The defined meal plan.

\begin{tabular}{|c|c|c|c|c|}
\hline Day & $\begin{array}{c}1 \\
\text { Run-in day }\end{array}$ & $\begin{array}{c}2 \\
\text { Study day }\end{array}$ & $\begin{array}{c}3 \\
\text { Study day }\end{array}$ & $\begin{array}{c}4 \\
\text { Study day }\end{array}$ \\
\hline Breakfast & Training - GTT & GTT 1 & GTT 2 & GTT 3 \\
\hline $7: 00$ & Glucose $(50 \mathrm{~g})$ & Glucose (50 g) & Glucose (50 g) & Glucose (50 g) \\
\hline $\begin{array}{l}\text { Lunch } \\
11: 00\end{array}$ & $\begin{array}{l}\text { Ham+Multigrain Rye } \\
\text { Knäckebrot }\end{array}$ & $\begin{array}{l}\text { Rolled Wafers } \\
\text { with vanilla-cinnamon }\end{array}$ & $\begin{array}{l}\text { Multigrain Rye } \\
\text { Knäckebrot }\end{array}$ & $\begin{array}{l}\text { End of the study } \\
\text { at } 11.00 \mathrm{~h}\end{array}$ \\
\hline $\begin{array}{l}\text { Snack } \\
15: 00\end{array}$ & $\begin{array}{l}\text { Rolled Wafers } \\
\text { with vanilla-cinnamon }\end{array}$ & $\begin{array}{l}\text { Multigrain Rye } \\
\text { Knäckebrot }\end{array}$ & $\begin{array}{l}\text { Yogurt Florian } \\
+ \text { Multigrain Rye } \\
\text { Knäckebrot }\end{array}$ & \\
\hline $\begin{array}{l}\text { Dinner } 1 \\
\text { 19:00 }\end{array}$ & $\begin{array}{l}\text { Multigrain Rye } \\
\text { Knäckebrot }\end{array}$ & $\begin{array}{l}\text { Yogurt Florian + } \\
\text { Multigrain Rye } \\
\text { Knäckebrot }\end{array}$ & $\begin{array}{l}\text { Ham + Multigrain Rye } \\
\text { Knäckebrot }\end{array}$ & \\
\hline $\begin{array}{l}\text { Dinner } 2 \\
23: 00\end{array}$ & $\begin{array}{l}\text { Yogurt Florian } \\
+ \text { Multigrain Rye } \\
\text { Knäckebrot }\end{array}$ & $\begin{array}{l}\text { Ham } \\
+ \text { Multigrain Rye } \\
\text { Knäckebrot }\end{array}$ & $\begin{array}{l}\text { Rolled Wafers } \\
\text { with vanilla-cinnamon }\end{array}$ & \\
\hline
\end{tabular}


Table 2. Delay between glucose concentration in tissue and plasma during the increase of plasma glucose (BT $\uparrow$ ) and decrease of plasma glucose (TB $\downarrow$ ) in HP, DM1 and DM2.

\begin{tabular}{|c|c|c|c|c|c|}
\hline & \multirow{2}{*}{$\begin{array}{c}\text { Person } \\
\text { No }\end{array}$} & \multicolumn{2}{|c|}{$\mathrm{BT} \uparrow[\mathrm{min}]$} & \multicolumn{2}{|c|}{$\mathrm{TB} \downarrow[\min ]$} \\
\hline & & Mean & SD & Mean & SD \\
\hline \multirow[t]{4}{*}{ HP } & $\mathrm{P} 08$ & - & - & - & - \\
\hline & P21 & - & - & - & - \\
\hline & P22 & 4 & - & 30 & - \\
\hline & P24 & 12 & 0 & 14 & 1.4 \\
\hline \multirow[t]{4}{*}{$\mathrm{DM} 1$} & P06 & - & - & - & - \\
\hline & P11 & 8 & 7 & 37 & 20 \\
\hline & P17 & - & - & 27 & - \\
\hline & P18 & 18 & 9 & 36 & 18 \\
\hline \multirow[t]{4}{*}{ DM 2} & P01 & - & - & - & - \\
\hline & P02 & - & - & - & - \\
\hline & P15 & 20 & 6 & 123 & - \\
\hline & P23 & 7 & 4 & 19 & 9 \\
\hline
\end{tabular}

(- | -) no agreement between trends in CGMS (tissue ISIG calibrated for capillary plasma) and Beckman (venous plasma)

(x $\mid$-) one agreement between trends in CGMS (tissue ISIG calibrated for capillary plasma) and Beckman (venous plasma)

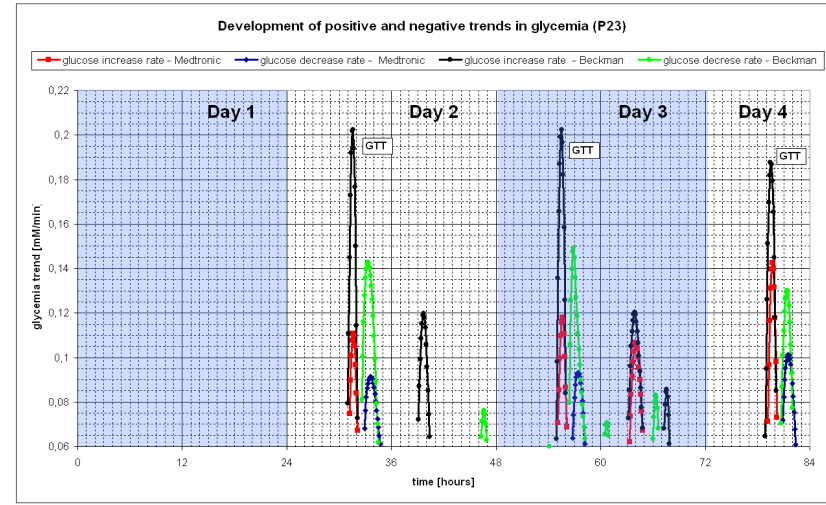

Fig. 1. Comparison of the Beckman and CGSM-Medtronic trend results.

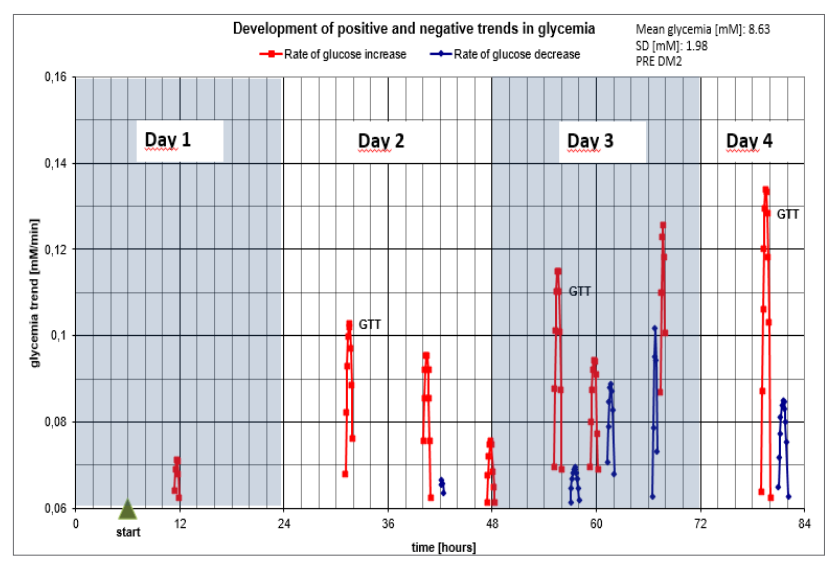

Fig. 3. Development of positive and negative trends in glycaemia of a man with DM2 (P01).

The analysis of glucose increase/decrease (GID) rates is demonstrated in Fig. 2 - 4.

Fig. 2 shows the trends of GID in a healthy woman. The glucose controlling mechanism is able to compensate the glucose changes in an effective manner which

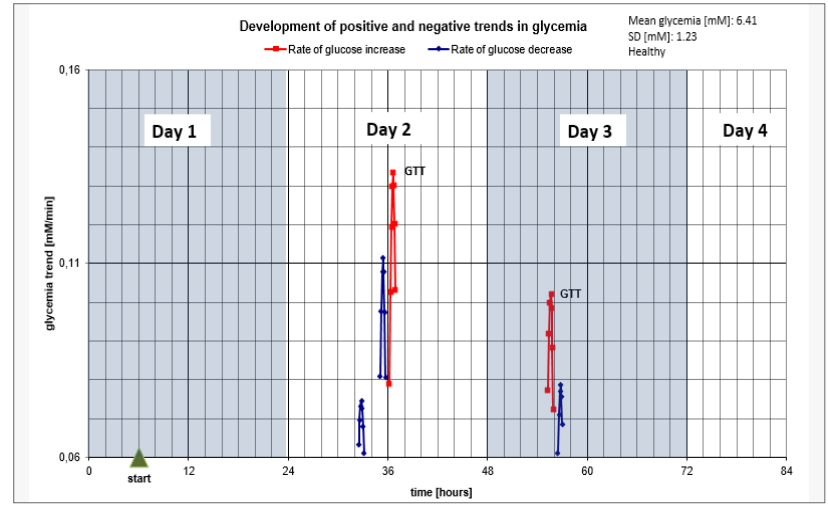

Fig. 2. Development of positive and negative trends in glycaemia of a healthy woman (P21).

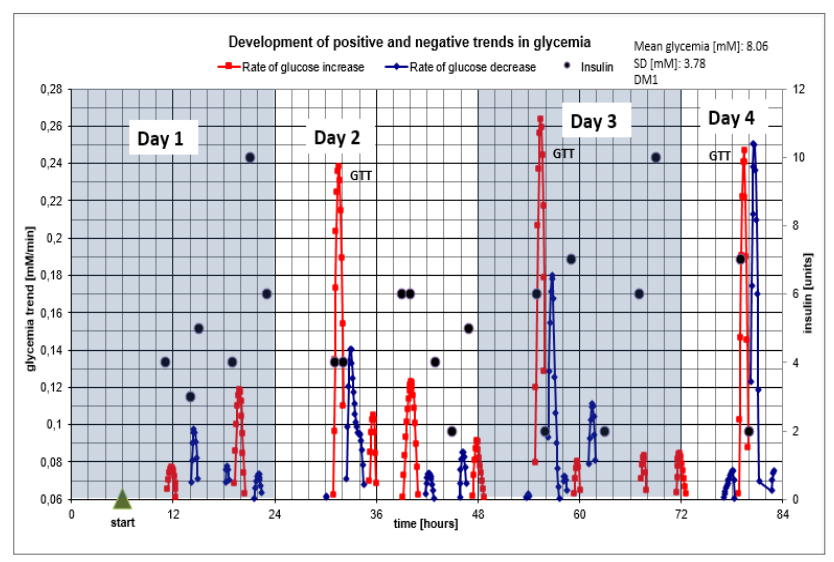

Fig. 4. Development of positive and negative trends in glycaemia of a man with newly diagnosed DM1 (P18) on intensive insulin treatment.

results in very small values of GID. The average glucose concentration during the test was $6.4 \mathrm{mmol} / \mathrm{L}$ (SD 1.25 $\mathrm{mmol} / \mathrm{L}$ ). The $3^{\text {rd }}$ GTT was fully compensated by the body glucose control mechanisms. No GID higher than 0.06 $\mathrm{mmol} / \mathrm{L} / \mathrm{min}$ was detected at the third GTT. No change 
rates could be recognized at the fourth GTT, which may be the result of excellent function of the B-cells.

Fig. 3 shows the trends of GID in a man with DM2. The average glucose concentration is 8.6 (SD 1.98) $\mathrm{mmol} / \mathrm{L}$. Repetition of GTT starts to disrupt glucose metabolism (day 2) and the worsening continues on days 3 and 4 . This phenomenon was observed in 10 volunteers (healthy, DM1, DM2) out of 12.

Fig. 4 shows the GID of a volunteer with recent DM1 on insulin. At the beginning (day 1), his control is quite good, and the pancreas seems to function adequately. The GID response in the course of GTT was about 0.1 $\mathrm{mmol} / \mathrm{L} / \mathrm{min}$ which is comparable to a healthy person. However, as early as on day 2, the GTT load could not be adequately controlled either by injections of exogenous insulin or by the resting function of the pancreas. The glucose increases at a rate of $0.24-0.26 \mathrm{mmol} / \mathrm{L} / \mathrm{min}$ and this increase is followed by a large decrease ranging from $0.14 \mathrm{mmol} / \mathrm{L} / \mathrm{min}$ after the first GTT to $0.25 \mathrm{mmol} / \mathrm{L} /$ min after the third GTT.

\section{DISCUSSION}

This pilot study provides insight into important parameters of glycaemic control. The outcomes support the value of precise estimation of time lag and change rates between glucose concentrations in plasma and interstitium in the course of rising and falling. In this way it contributes to improving diagnostic procedures and the efficacy of diabetes treatment.

Although the results are limited due to the small sample size they provide valuable data for improving the standard of diabetes therapy and the design of coming studies.

The threshold (limit) of GID rates between healthy and DM1 and DM2 volunteers was found to be 0.1 $\mathrm{mmol} / \mathrm{L} / \mathrm{min}$. This value is the result of the present $\mathrm{pi}-$ lot study but needs to be confirmed by studies on larger numbers of volunteers.

The importance of CGMS in effective therapeutic outcomes has been clearly demonstrated by a number of previous studies. On the other hand, in some cases low reliability of CGMS in measuring the glucose concentration change rates is also reported. These contradictory issues cannot be neglected. In people with diabetes, the glucose control system of the body needs hours to recover after glucose intake. A stimulus can initiate the oscillations. In this study, the effect of the GTT repetition on glucose tolerance was found in volunteers with diabetes (Fig. 3 and 4) but not in healthy people (Fig. 2). Therefore, continuous monitoring of glucose concentration in venous plasma in the course of OGTT appears to be necessary to predict the glucose load consequences. The results for a man with recent DM1 shown in Fig. 4 suggest that the glucose load on the first day was probably balanced not only by exogenous insulin but also by resting insulin secretion of the B-cells. Given the increased GID rates on days 2, 3 and 4, the B-cells appear to be already exhausted due to repeated glucose load.
The CGMS in this study (using the monitor Guardian) was applied to monitor the state of the patient, even though recent versions of monitors and insulin pumps include processing of trends of increase/decrease of glucose concentrations which distinguish change rates of 0.11 $\mathrm{mmol} / \mathrm{L} / \mathrm{min}$ (marked on the display by one arrow) and of $0.22 \mathrm{mmol} / \mathrm{L} / \mathrm{min}$ (marked by two arrows).

If all experimental conditions comply with ideal measuring conditions, excellent agreement between CGMS and Beckman is found (Fig. 1). However, such agreement was found only in 1/12 volunteers. Table 2 shows quite convincingly that the lag time between blood glucose and interstitial fluid glucose varies considerably between cases. Possible reasons for the poor correlation between these two compartments include physiological factors such as temperature, blood perfusion, osmolality, actual glucose concentrations in intracellular vs. extracellular space, activity of glucose transporters, insulin concentration, state of the insulin receptors etc. These factors may vary between individuals and also be different at specific sites of the body. The potential influence of medication must also be considered.

This discussion confirms the importance of the development of a reliable and robust system which can measure the glucose concentrations to such an extent that the process of glucose metabolism can be measured and analysed in a continous manner and with sufficient time resolution. We found no commercial device which could provide such data.

The results of this pilot study are in accordance with the recent state of the art of development of closed loop systems using CGMS-augmented insulin pumps ${ }^{9,11,19,20}$.

\section{Example 1}

a) Plasma glucose concentration is $3.5 \mathrm{mmol} / \mathrm{L}$, ie. it is close to hypoglycaemia.

b) The approximate highest trend of plasma glucose concentration decrease/increase is $0.2 \mathrm{mmol} / \mathrm{L} / \mathrm{min}$ (as found in this study), i.e. $1 \mathrm{mmol} / \mathrm{L}$ in $5 \mathrm{~min}$.

c) In the course of five minutes, glycaemia may either fall from 3.5 to $2.5 \mathrm{mmol} / \mathrm{L}$ (which is hypoglycaemia) or rise to $4.5 \mathrm{mmol} / \mathrm{L}$ (which is euglycaemia).

d) Which steps should be considered? It is important not to interpret the patient's state as plasma glucose $3.5 \mathrm{mmol} / \mathrm{L}$, but as the point of its trajectory with possible trends. It is improbable that 5 minutes delay would cause a substantial deterioration of the state of the patient and that the patient would approach severe hypoglycemia. It is therefore appropriate to repeat the measurements after $5 \mathrm{~min}$. The decision is made on the basis of the trend between the last two measurements. If plasma glucose concentration decreases and the trend decreases further it is necessary to immediately take glucose. If, however, the trend increases significantly, and after $5 \mathrm{~min}$, the glucose concentration is $4 \mathrm{mmol} / \mathrm{L}$, it is clear that the patient should remain at rest, and should not take up glucose. Administration of glucose in the case of low plasma glucose concentration and its increasing trend will definitely lead to hyperglycaemia because time to absorb 
glucose varies from 10 to $15 \mathrm{~min}$. The whole system starts to oscillate. In other words the compensation system has deteriorated.

Example 2

a) Plasma glucose concentration is $15 \mathrm{mmol} / \mathrm{l}$, i.e. hyperglycaemia.

b) The approximate highest trend of plasma glucose concentration decrease/increase is $0.2 \mathrm{mmol} / \mathrm{L} / \mathrm{min}$ (as found in this study), i.e. $1 \mathrm{mmol} / \mathrm{L}$ in $5 \mathrm{~min}$.

c) In the course of five minutes, glycaemia may either fall to $14 \mathrm{mmol} / \mathrm{L}$ or rise to $16 \mathrm{mmol} / \mathrm{L}$ ).

d) Which steps should be considered? Plasma glucose concentration should be measured after 5 min. If a decreasing trend is detected, it might be a mistake to add insulin to restore normoglycemia. The addition of insulin might sometimes lead to overshoot to hypoglycaemia. For this reason, information on insulin available in the body, on food consumption and after muscular exercise is necessary, to assess the real needs for correction boluses. On the other hand, if, after 5 min, the glucose concentration increases above 15.5 $16 \mathrm{mmol} / \mathrm{L}$ the need for a correction bolus is evident.

The time has come to use CGM more widely in diabetes management and to introduce metrics that allow assessment of continuous glucose sensing for better glycemic control on a day-to-day basis. Data analysis software as well as computer-assisted decision support systems have the potential to optimize clinical decision making. Challenging research is on going. Several sophisticated studies are described elsewhere ${ }^{4}$ :

The International Diabetes Center, Minneapolis, USA, has developed the data analysis software program called Ambulatory Glucose Profile (AGP) "Dashboard" and issued recommendations for standardizing glucose reporting and analysis to optimize clinical decision making $^{21}$. To date, 10-point glycaemic profiles are applied in our diabetes center to correct diabetes management ${ }^{22}$.

To ease analysis of CGM and SMPG/SMBG data, Rodbard ${ }^{23}$ has presented a practical approach to defining reference values for measures of quality of glycemic control and measures of glycemic variability.

Another approach to evaluate the quality of glycaemic control from CGM profiles has been applied in Germany $^{24}$. Not only hyperglycaemia but also glucose oscilations were considered ${ }^{25-28}$

Rawlings ${ }^{29}$ created a user-friendly Continuous Glucose Monitoring User Interface for Diabetes Evaluation $\left(\mathrm{CGM} \mathrm{GUIDE}{ }^{\odot}\right)$. This interface calculates and displays multiple measures derived from CGM data. It allows for user-defined thresholds for hyper- and hypoglycemia and calculates the glucose variability measures.

In type 1 diabetes, software to adjust insulin dosage and adopt treatment regimens has been successfully introduced $^{30,31}$.

On the other hand, to generate computer-assisted decision support programs for type 2 diabetes has been difficult, because of its complex pathophysiology. The Karlsburg Diabetes Management System (KADIS ${ }^{\circledR}$ ), developed by a team of researchers at the Institute of Diabetes Karlsburg, Germany, has become available as a computer-based decision support for the management of type 2 diabetes, using input of CGM data for glycemic control and optimized diabetes therapy ${ }^{32}$. In outpatients with type 2 diabetes, utilizing KADIS ${ }^{\circledR}$ over three months demonstrated a net reduction in $\mathrm{A} 1 \mathrm{C}$ of $0.6 \%$ and time spent in hyperglycemia was reduced by $22 \%$ without increasing hypoglycemia.

Rodbard and Vigersky ${ }^{33}$ developed a computer-assisted decision support (CADS) for primary care providers to improve diabetes management in type 2 diabetes patients. This system is based on the input of SMBG/SMPG data, including clinical information.

Recent studies ${ }^{11,12,19,20,34,35}$, provide an optimistic outlook on perspectives for advanced technologies for the treatment of diabetes.

In summary, the practical outcomes from the repeated OGTTs in our 4-day pilot study in volunteers tested when lying in bed and keeping to the defined meal plan:

(1) The time delay (lag phase) between glucose concentrations in plasma and tissue in the course of their increase/decrease was in HP 4-12 min/14-30 min, in DM1 0-18 $\mathrm{min} / 27-37 \mathrm{~min}$ and in DM2 7-20 min/19-123 min. The delays appear to be longer in people with diabetes than in healthy persons. The decrease in glucose concentration always lasted longer than the increase.

(2) The maximum glucose increase/decrease rate in $\mathrm{HP}<0.1 \mathrm{mmol} / \mathrm{L} / \mathrm{min}$. In DM1 and DM2, the maximum glucose increase rate was $0.25 \mathrm{mmol} / \mathrm{L} / \mathrm{min} /$ and the maximum glucose decrease rate was mostly $0.15 \mathrm{mmol} / \mathrm{L} / \mathrm{min}$ with one extreme value of $0.25 \mathrm{mmol} / \mathrm{L} / \mathrm{min}$.

Hence, considering the assessment of various disorders of carbohydrate metabolism, the glucose increase/ decrease rates appear to be more sensitive than oral GTT alone. Therefore, in addition to AGP, ketones, HbA1c and insulin sensitivity (HOMA), the metabolic state characteristics should be completed by information on lag-phase and maximum GID rates in GTT. Further studies considering the lag phase for the adjustment of euglycaemiaoriented therapy are underway.

Acknowledgement: Parts of this paper were presented as a Poster at the 50th Annual Meeting of European Association for the Study of Diabetes, Vienna, Austria, September 15-19, 2014.

This work was supported by project MIDI financed by Probe Scientific Ltd., UK. The authors express appreciation to Palacky University Olomouc for support.

Author contributions: RC, JK, MOC: study design, data processing and interpretation, literature search, manuscript writing; BS, RP, LJ: preparation of study run, data collection and statistical analysis; TB: data processing, figures; BD: laboratory analysis, supervision of laboratory procedures and equipment; HZ, ED: meal plan and CGMS, blood data collection; JV: technical assistance, figures; JB: manuscript writing, literature search.

Conflict of interest statement: RC: participation in clinical studies on insulin pumps was supported by Medtronic 
Minimed International; MOC: employees, Probe Scientific Ltd, Bedford, United Kingdom; BS, JK, RP, LJ, JV: employee, BVT Technologies, a.s., Strazek, Czech Republic; TB, BD, HZ, ED, JB: none conflict of interest.

\section{REFERENCES}

1. Takahashi S, Uchino H, Shimizu T, Kanazawa A, Tamura Y, Sakai K, Watada H, Hirose T, Kawamori R, Tanaka Y. Comparison of glycated albumin (GA) and gycated hemoglobin ( $\mathrm{HbA} 1 \mathrm{c})$ in type 2 diabetic patients: usefulness of GA for evaluation of short-term changes in glycemic control. Endocr J 2007;54(1):139-44.

2. Dungan KM. 1,5-anhydroglucitol (GlycoMark ${ }^{\mathrm{TM}}$ ) as a marker of shortterm glycemic control and glycemic excursions. Expert Rev Mol Diagn 2008;8(1):9-19.

3. Rodbard D. Interpretation of continuous glucose monitoring data: glycemic variability and quality of glycemic control. Diabetes Technol Ther 2009;11(Suppl 1):S55-S65.

4. Kohnert K-D, Heinke P, Vogt L, Meyramov GG, Salzsieder E. Optimizing diabetes management: comprehensive analysis of glucose monitoring data and use of better metrics for glycemic control. Bulletin of the Karaganda University 2013;4(72):6-15.

5. Peterson K, Chlup R, Zapletalová J, Kohnert K, Kudlová P, Bartek J, Nakládalová M, Doubravová B, Sečkař P. Influence of oral antidiabetic drugs on hyperglycemic response to foods in persons with type 2 diabetes mellitus as assessed by continuous glucose monitoring system:a pilot study. J Diab Sci Tech 2010;4(4):983-92.

6. Chlup R, Doubravová B, Bartek J, Zapletalová J, Krystyník O, Procházka V. Effective assessment of diabetes control using personal glucometers (Contourlink, Bayer, Germany; Calla, Wellion, Austria Linus, Agamatrix, USA). Disease Markers 2013;35(6):895-905.

7. Mlčák P, Fialová J, Trnková K, Chlup R. A continuous glucose monitoring system (CGMS) - a promising aproach for improving metabolic control in persons with type 1 diabetes mellitus treated by insulin pumps. Biomed Papers 2004;148(1):33-8.

8. Juvenile Diabetes Research Foundation Continuous Glucose Monitoring Study Group, Bode B, Beck RW, Xing D, Gilliam L, Hirsch I, Kollman C, Laffel L, Ruedy KJ, Tamborlane WV, Weinzimer S, Wolpert $\mathrm{H}$. Sustained benefit of continuous glucose monitoring on $\mathrm{HbA} 1 \mathrm{C}$ glucose profiles, and hypoglycemia in adults with type 1 diabetes. Diabetes Care 2009;32(11):2047-9.

9. Cohen O, Körner A, Chlup R, Zoupas C, Rahozin A, Wudi K, Bartášková D, Pappas A, Niederland T, Taybani Z, Barák L, Vazeou AS. Improved glycemic control through continuous glucose sensor - augmented insulin pump therapy: Prospective results from a community and academic practice patient registry. J Diab Sci Techn 2009;3(4):804-11.

10. Peterson K, Zapletalová J, Kudlová P, Matušková V, Bartek J, Novotný D, Chlup R. Benefits of three-month continuous glucose monitoring for persons with diabetes using insulin pumps and sensors. Biomed Papers 2009;153(1):47-52.

11. Battelino T, Conget I, Olsen B, Schütz-Fuhrmann I, Hommel E, Hoogma R, Schierloh U, Sulli N, Bolinder J; SWITCH Study Group. The use and efficacy of continuous glucose monitoring in type 1 diabetes treated with insulin pump therapy: a randomised controlled trial. Diabetologia 2012;55:3155-62.

12. Vigersky RA, Fonda SJ, Chellappa M, Walker MS, Ehrhardt MN. Shortand long-term effects of real-time continuous glucose monitoring in patients with type 2 diabetes. Diabetes Care 2012;35(1):32-8.

13. Poljaková I, Elšíková E, Chlup R, Kalabus S, Hasala O, Zapletalová J. Glucose sensing module - is it time to integrate it into real-time perioperative monitoring? An observational pilot study with subcutaneous sensors. Biomed Pap Med Fac Univ Palacky Olomouc Czech Rep 2013;157(4):346-57.

14. Chlup R, Jelenová D, Kudlová P, Chlupová K, Bartek J, Zapletalová J, Langová K, Chlupová L. Continuous glucose monitoring - novel approach to the determination of the glycaemic index of foods (DEGIF 1 ); Determination of the glycaemic index of foods by means of the CGMS. Exp Clin Endocrinol Diab 2006;144(12):68-74.

15. Chlup R, Peterson K, Zapletalová J, Kudlová P, Sečkař P. Extended prandial glycemic profiles of foods as assessed using continuous glucose monitoring enhance the power of the 120-minute glycemic index. J Diab Sci Tech 2010;4(3):615-24.

16. Rebrin K, Steil GM. Can Interstitial Glucose Assessment Replace Blood Glucose Measurements? Diabetes Technology \& Therapeutics. October 2000;2(3):461-72. doi:10.1089/15209150050194332.

17. Thennadil SN, Rennert JL, Wenzel BJ, Hazen KH, Ruchti TL, Block MB. Comparison of glucose concentration in interstitial fluid, and capillary and venous blood during rapid changes in blood glucose levels. Diabetes Technology \& Therapeutics. 2001;3(3):357-65. doi:10.1089/15209150152607132.

18. Boyne MS, Silver DM, Kaplan J, Saudek CD. Timing of changes in interstitial and venous blood glucose measured with a continuous subcutaneous glucose sensor. Diabetes 2003;52(11):2790-4. doi: 10.2337/diabetes.52.11.2790.

19. Hovorka R, Nodale M. Response to Mitre et al.: Analysis of Continuous Glucose Monitoring Data to Assess Outpatient Closed-Loop Studies: Considerations for Different Sensors. Diabetes Technology \& Therapeutics 2014;16(5):328-9. doi:10.1089/dia.2013.0336.38.

20. Leelarathna L, Dellweg S, Mader JK, Allen JM, Benesch C, Doll W, Ellmerer M, Hartnell S, Heinemann L, Kojzar H, Michalewski L, Nodale M, Thabit H, Wilinska ME, Pieber TR, Arnolds S, Evans ML, Hovorka R; AP@home Consortium. Day and night home closed-loop insulin delivery in adults with type 1 diabetes: three-center randomized crossover study. Diabetes Care 2014; 37(7):1931-7.

21. Bergenstal RM, Ahmann AJ, Bailey T, Beck RW, Bissen J, Buckingham B, Deeb L, Dolin RH, Garg SK, Goland R, Hirsch IB, Klonoff DC, Kruger DF, Matfin G, Mazze RS, Olson BA, Parkin C, Peters A, Powers MA, Rodriguez H, Southerland P, Strock ES, Tamborlane W, Wesley DM. Recommendations for standardizing glucose reporting and analysis to optimize clinical decision making in diabetes: the Ambulatory Glucose Profile (AGP). Diabetes Technol Ther 2013;15(3):198-211. doi: 10.1089/dia.2013.0051.

22. Chlup R, Krystynik O, Nadvornikova M, Zalesakova M, Durajkova E, Poljakova I, Kudlova P, Bartek J, Zapletalova J, Prochazka V. Benefits of advanced technologies for optimum therapy of type 1 and type 2 diabetes in practice. (Moderní technologie a způsob jejich využívání pro optimalizaci léčby diabetu 1. i 2. typu v praxi). Klin Farmakol Farmacie 2014;28(2):72-9.

23. Rodbard D. Clinical interpretation of indices of quality of glycemic control and glycemic variability. Postgrad Med 2011;123(4):107-18.

24. Salzsieder E, Vogt L, Heinke P, Augstein P. Q-score: a new tool for objective assessment and verification of the quality of continuously measured glucose profiles. Diabetologie und Stoffwechsel 2011;6:223.

25. Kohnert KD, Vogt L, Salzsieder E. Advances in understanding glucose variability and the role of continuous glucose monitoring. European Endocrinol 2010;6(1):53-56.

26. Fritzsche $G$, Kohnert KD, Heinke P, Vogt L, Salzsieder E. The use of a computer program to calculate the mean amplitude of glycemic excursions. Diabetes Technol Ther 2011;13(3):319-25.

27. Kohnert KD, Augstein P, Heinke P, Zander E, Peterson K, Freyse EJ, Salzsieder E. Chronic hyperglycemia but not glucose variability determines $\mathrm{HbA} 1 \mathrm{c}$ levels in well-controlled patients with type 2 diabetes. Diabetes Res Clin Pract 2007;77(3):420-6.

28. Kohnert KD, Augstein P, Zander E, Heinke P, Peterson K, Freyse EJ, Hovorka R, Salzsieder E. Glycemic variability correlates strongly with postprandial beta-cell dysfunction in a segment of type 2 diabetic patients using oral hypoglycemic agents. Diabetes Care 2009;32(6):1058-62.

29. Rawlings RA, Shi H, Yuan LH, Brehm W, Pop-Busui R, Nelson PW. Translating glucose variability metrics into the clinic via continuous glucose monitoring: a graphical user interface for diabetes evaluation (CGM-GUIDE@)// Diabetes Technol Ther 2011;13(12):1241-8.

30. Rutscher A, Salzsieder E, Thierbach U, Fischer U, Albrecht G. KADIS - a computer-aided decision support system for improving the management of type-I diabetes. Exp Clin Endocrinol 1990;95(1):137-47.

31. Augstein P, Vogt L, Kohnert KD, Freyse EJ, Heinke P, Salzsieder E. Outpatient assessment of Karlsburg Diabetes Management Systembased decision support. Diabetes Care 2007;30(7):1704-8.

32. Salzsieder E, Vogt L, Kohnert KD, Heinke P, Augstein P. Model-based decision support in diabetes care. Comput Methods Prog Biomed 2011;102(2):206-18

33. Rodbard D, Vigersky RA. Design of a decision support system to help 
clinicians manage glycemia in patients with type 2 diabetes mellitus. J Diabetes Sci Technol 2011;5(2):402-11.

34. Mastrototaro J, Welsh JB, Lee S. Practical considerations in the use of real-time continuous glucose monitoring alerts. J Diabetes Sci Technol 2010;4(3):733-9.

35. Reznik Y, Cohen O, Aronson R, Conget I, Runzis S, Castaneda J, Lee
SW. Insulin pump treatment compared with multiple daily injections for treatment of type 2 diabetes (OpT2mise): a randomised openlabel controlled trial. The Lancet. Jul $2014 \mathrm{E}$ pub ahead of print doi: 10.1016/S0140-6736(14)61037-0. 